\title{
Erratum to: Microstructural Evolution of Chloride-Cleaned Silicon Carbide Aluminum Composites
}

\author{
S.O. ADEOSUN, ${ }^{1}$ E.I. AKPAN ${ }^{2},{ }^{2,4}$ O.P. GBENEBOR,${ }^{1}$ and S.A. BALOGUN ${ }^{3}$ \\ 1.-Department of Metallurgical and Materials Engineering, University of Lagos, Lagos, Nigeria. \\ 2.-Department of Materials and Production Engineering, Ambrose Alli University, Ekpoma, \\ Nigeria. 3.-Department of Mechanical and Biomedical Engineering, Bells University of Tech- \\ nology, Ota, Nigeria. 4.—e-mail: emma_eia@yahoo.com
}

\section{Erratum to: JOM \\ DOI: 10.1007/s11837-015-1717-9}

This article was originally published without financial acknowledgements. They appear here in their entirety.

Acknowledgements The research group acknowledge with grateful thanks the University of Lagos for providing the platform for the TETFUND RESEARCH GRANT (CRC/TETFUND/NO. 2011/2013) used for this research. We are also grateful for the assistance provided by $\mathrm{Mr}$ W.A. Ayoola, Olajide Kehinde and the staff of Metallurgical and Materials Engineering Laboratory and Foundry shop University of Lagos. 